\title{
Normative References and Clinical Correlates of Fetal Umbilical Artery Doppler Indices in Ile-Ife, Southwest, Nigeria.
}

Ibraheem Olayemi Awowole ( $\square$ drawo2001@yahoo.com )

Obafemi Awolowo University Faculty of Clinical Sciences https://orcid.org/0000-0001-7006-0824

Oluwafemi Kuti

Obafemi Awolowo University Faculty of Clinical Sciences

Christianah Mopelola Asaleye

Obafemi Awolowo University faculty of clinical sciences

Olusegun Olalekan Badejoko

Obafemi Awolowo University Faculty of Clinical Sciences

\section{Sekinah Bolanle Bola-Oyebamiji}

Ladoke Akintola University of Technology College of Health Sciences

Richard Busayo Olatunji

University of Ibadan College of Medicine

Oluwaseun Oludotun Sowemimo

Obafemi Awolowo University Faculty of Clinical Sciences

Sidiqat Abiola Ayodele

Lagos State University Teaching Hospital

\section{Research article}

Keywords: Umbilical artery Doppler, Pulsatility index, Reference ranges, Resistance index, Systolic:diastolic ratio, Growth restriction

Posted Date: August 12th, 2019

DOI: https://doi.org/10.21203/rs.2.12631/v1

License: (c) (i) This work is licensed under a Creative Commons Attribution 4.0 International License. Read Full License 


\section{Abstract}

Background The unacceptably high stillbirth rate in Nigeria, which results mainly from antepartum fetal death demands evidence-based antenatal interventions. While evidence suggests that fetal surveillance using umbilical artery (UA) Doppler reduces perinatal mortality; normative references of fetal UA Doppler indices are not readily available in Nigeria. This study aims to construct indigenous, gestational age-specific normative references for fetal UA Pulsatility Index (PI), Resistance Index (RI) and Systolic/Diastolic ratio $(\mathrm{S}: \mathrm{D})$ of singleton pregnancies in lle-Ife, Nigeria, and correlate this with pregnancy outcomes. Methods In a longitudinal study involving 415 women with singleton fetuses between the gestational ages of 26-40weeks at the Obafemi Awolowo University Teaching Hospital, Nigeria, fetal umbilical artery PI, RI and S:D were measured four-weekly till delivery. The means and normative centiles ( $95 \%$ range between 2.5 th -97.5 th) of the indices were determined. Regression equations were generated for the three indices, and Pearson's correlation was used to establish the relationship with maternal age, parity, gestational age (GA) and birth weight. Results The three indices demonstrated significant inverse correlation with GA, such that the RI reduced by 0.013 , while the $\mathrm{PI}$ and S:D ratio reduced by 0.027 and 0.71 respectively for each additional week of pregnancy. There was a significant negative correlation between the $\mathrm{RI}(r=-0.207 ; p=0.001), \mathrm{PI}(r=-0.17$; $p=0.01), S: D$ ratio $(r=-0.25 ; p<0.001)$ and birth weight, but not with maternal age and parity. The regression equations were $\mathrm{RI}=1.004-0.013(\mathrm{x}), \mathrm{PI}=1.78-0.027(\mathrm{x})$ and $\mathrm{S}: \mathrm{D}=4.77-0.71(\mathrm{x})$ (where $\mathrm{x}=\mathrm{GA}$ in weeks). Conclusion The fetal umbilical artery Doppler indices decreased progressively with advancing GA. There was a significant reverse-association with birthweight, but not with maternal age or parity. This study has generated, gestational age-specific umbilical artery Doppler normative references ideal for the local population's antepartum fetal assessment.

\section{Background}

Stillbirth is an unwanted obstetric outcome that combines birth and death in one event. With about 2.6 million stillbirths annually, it ranks fifth on the list of causes of deaths worldwide.Majority of the 2.6 million annual stillbirths occur in the antepartum period,(1-3) with fetal growth restriction (FGR) from placental insufficiency being the leading cause.(4)Prompt recognition and management of FGR will therefore significantly reduce both antepartum and intrapartum stillbirths. Two-thirds of all global stillbirths occur in Africa and South-East Asia alone.(1) In sub-Saharan Africa, the stillbirth rate is approximately ten times that of developed countries. Despite a sizable proportion of stillbirths being unreported in the country,Nigeria, with a stillbirth rate of 71/1000 delivery, together with four other countries account for half of all global stillbirths. (5)

Doppler study of selected fetal organs has been shown by meta-analysis to improve stillbirth rates in pregnancies at risk of placental insufficiency without increasing unnecessary obstetric interventions.(6-9) The umbilical artery Doppler is superior to other techniques of antepartum surveillance in the early detection of FGR when utilized in pregnancies at risk, $(10,11)$ and deterioration of the Doppler indices (Pulsatility Index $(\mathrm{PI})$; Systolic/Diastolic ratio (S/D); and the Resistance Index (RI))(12-14) is useful in timing the delivery of preterm, growth-restricted fetuses. $(15,16)$ The hallmark of this practice is the ability to discern abnormal 
results, and translate this to a corresponding degree of clinical severity or fetal compromise using appropriate normative references.

Despite the high perinatal mortality rate in Nigeria and the proven benefit of UA Doppler, optimal utilization of this tool is hindered by the unavailability of Doppler facilities in many hospitals. Where such facilities are available, interpretation and clinical applicability are challenged by the unavailability of population-specific normative references for the indices, despite evidence that significant variations in Doppler velocimetry exist among different ethnic groups. (17) Consequently, only few Nigerian studies $(18,19)$ have applied Doppler velocimetry in the evaluation of fetal status in utero. This study therefore aims to establish populationspecific normative references for the fetal umbilical artery Doppler indices at the Obafemi Awolowo University Teaching Hospitals Complex, lle-lfe, Nigeria and correlate this with maternal clinical parameters and fetal outcome.

\section{Methods}

This longitudinal study was conducted at the Perinatal Unit of the Obafemi Awolowo University Teaching Hospitals Complex, lle-lfe between July 2015 and March 2019. The participants comprised women with singleton pregnancies whose gestational age had been confirmed with a crown-rump length measurement between the gestational age of $11-13^{+6}$ weeks. An anatomy scan was performed between 19-22 weeks and only women with structurally normal fetuses were recruited. Measurement of the umbilical artery Doppler indices was commenced at a gestational age $\geq 26$ weeks, but not later than 28 weeks. This was repeated four-weekly till delivery; only pregnancies that resulted in the delivery of live, normal babies were included in the final analysis.

The scans were done with a Mindray DC-6, (Shenzhen Mindray Bio-medical Electronics ${ }^{\circledR}$ ) using a 2.5$6.0 \mathrm{MHz}$ curvilinear probe. The umbilical vessels were first identified with colour Doppler with the high-pass filter set at low; the pulsed wave Doppler was then activated, with the sample volume adjusted to $5 \mathrm{~mm}$, such that it covered only the vessel that was being sampled. An angle of insonation less than $15^{\circ}$ was targeted for all measurements; manual correction of the angle was performed when this could not be achieved. A sonogram with at least five uniform waveforms was obtained during a period of fetal apnea, and the wave with the highest peak systolic velocity was chosen as a representative image. Multiple measurements of the $\mathrm{PI}, \mathrm{RI}$ and S/D ratio were taken using free loops of the umbilical cord by the same sonologist (IOA). The indices were automatically generated by the machine using the pre-installed formulae. The Mechanical Index was kept at $<1.0$, while the Thermal index was kept at $<1.5$ during the Doppler scans. $(20,21)$ The babies were weighed within 30 minutes of delivery to the nearest $0.1 \mathrm{~g}$ using an electronic scale.

The data were analysed with IBM SPSS $® 20.0$. The $95 \%$ normative reference range between the $2.5^{\text {th }}$ and $97.5^{\text {th }}$ centiles was constructed for each index. The Shapiro-Wilks test and the Quantile-to-Quantile (Q-Q) plots were used to assess the indices for normality; the PI and SD ratio were not normally distributed and were therefore normalised using logarithmic transformation. Logistic regression was applied to evaluate the relationship between the indices and gestational age, generating regression equations in the process. The 
relationship between the Doppler indices and feto-maternal characteristics such as maternal age, parity, neonatal gender and birthweight were tested with Pearson correlation.

\section{Results}

Four hundred and fifty women were recruited for the study. Twenty-seven of them (6.0\%) developed hypertension in pregnancy, while nineteen (4.22\%) had abdominal circumference and estimated fetal weight $<5^{\text {th }}$ centile of expected for gestational age \pm oligohydramnios. Thirty-five women (7.7\%) delivered outside our facility and the outcome of their pregnancies could not be ascertained; they were therefore excluded from further analysis, leaving four hundred and fifteen women, from whom 1375 Doppler measurements for each of the three indices were obtained for the construction of the reference centiles.

The ages of the women ranged between 18-45 years, with a mean of $31.01 \pm 4.43$ years, and their parity ranged between $0-6$, with a median of 2 . Two hundred and fifty-six (61.7\%) of the babies were male, with an overall caesarean section rate of $47.2 \%$. The mean birthweight of the babies was $3210 \pm 490 \mathrm{~g}$.

The umbilical artery RI, PI and S:D ratio for each week of gestation are depicted on tables 1,2 and 3 respectively. The three indices demonstrated a significantly negative correlation with gestational age, reducing progressively as gestation advanced (figures 1-3). Using regression analysis, for every additional week of gestation, the RI decreased by 0.013 , while the PI and S:D ratio decreased by 0.027 and 0.71 respectively. The regression equations for the three indices are presented as follows; $\mathrm{RI}=1.004-0.013(\mathrm{x})$, $\mathrm{PI}$ $=1.78-0.027(x)$ and S:D ratio $=4.77-0.71(x)$ (where $x=$ gestational age at Doppler assessment in weeks) .

There was a strong positive correlation between the RI and $\mathrm{PI}(r=0.87 ; \mathrm{P}<0.001)$, RI and S/D ratio ( $r=0.86$; $p<0.001)$ as well as PI and SD ratio $(r=.90 ; p<0.001)$. The indices however demonstrated a significantly negative correlation with the birthweight of the newborns (table 4). There was no significant correlation between the Doppler indices and maternal age, parity and fetal gender.

\section{Discussion}

In the absence of effective in-utero therapies for preterm growth restricted fetuses, maintaining the delicate balance between iatrogenic preterm birth with its attending complications, and continued intra-uterine stay remains the most critical decision. $(10,16,22)$ Utilization of the umbilical artery Doppler velocimetry is currently one of the most useful tools for such antenatal assessment.(8) To achieve this, clinicians must be able to discern normal from abnormal results, and this is best achieved using the reference derived from a similar population.(17) In line with this global trend therefore, this population-specific normative references for fetal umbilical artery Resistance Index, Pulsatility Index and Systolic/Diastolic ratio were constructed from an African population at the Obafemi Awolowo University Teaching Hospitals Complex, Ile-Ife, Nigeria.

The three indices decreased progressively, demonstrating significant reverse correlations with advancing gestational age. This pattern conforms with the trend that was observed from earlier reports among Caucasian populations, and further buttresses the need for gestational age-specific normative references, as no single cut-off would be appropriate across the entire duration of pregnancy. (23-25) 
A significant reverse correlation was observed between the umbilical artery Doppler indices and the birth weight of the babies, as previously reported by Acharya et al. $(23,26)$ This reflects the effect of increased cardiac output and placental perfusion in low impedance circulations, translating into the increased delivery of oxygenated blood and nutrients, with salubrious effects on fetal growth. The converse also holds true, with low birth weight sequel to high impedance placental circulation. $(24,27)$

There was no significant correlation between the maternal age, parity, fetal gender and the three Doppler indices. Consequently, it is hypothesized that the reference centiles created in this study may be utilized for any woman with high risk pregnancy, irrespective of her age and parity. While an earlier study had reported that there was no significant correlation with fetal gender,(23) another study recently reported significant differences across gestational ages based on fetal gender(17); this study did not detect any significant correlation between the indices and fetal gender.

Albeit discovered by different people and calculated using different formulae, (12-14) the three Doppler indices in this study demonstrated strong positive correlations, in agreement with findings from earlier studies. Consequently, any of the indices may be utilized in fetal monitoring in utero, except in the peculiar situation where the end diastolic flow is absent, when the S:D ratio may approach infinity and the Resistance Index equals 1, and are therefore unreliable.

While the use of fixed reference points such as the fetal end or the placental end of the umbilical cord had been previously reported, the use of free-floating loops of umbilical cord for Doppler velocimetry has remained popular in clinical practice due to the ease with which the loop can be identified(28); the free loop of the cord was therefore adopted for this study. It is noted that a previous study had been conducted from our centre with similar objectives. The previous study however adopted a cross-sectional methodology, thereby sampling each fetus once, without a rigorous technique of dating. The study also did not report the outcomes of the pregnancies. These limitations have been addressed in this study by ensuring that the reference centiles were derived from the same cohort of women.

The normative centiles derived from this study will be useful in the management of high-risk pregnancies complicated by hypertension and fetal growth restriction, especially in Nigeria where the incidence of stillbirths remains high. Further researches exploring the role of umbilical artery Doppler velocimetry in high risk pregnancies in developing countries, including possibly a systematic review of associated benefits are advocated.

\section{Conclusions}

Indigenous umbilical artery Doppler normative references are not yet popular in Nigeria, despite the high perinatal morbidity and mortality rates in the country, leaving the care of women with pregnancies at high risk of placental insufficiency to Obstetricians' personal preferences and experience. It is expected that the normative references generated in this study will provide a useful tool for antepartum fetal assessment of high-risk pregnancies, thereby contributing to the ongoing nationwide efforts at reducing the unacceptably high adverse perinatal outcomes in the country. 


\section{Abbreviations}

FGR: Fetal Growth Restriction

GA: Gestational age

OAUTHC: Obafemi Awolowo University Teaching Hospitals Complex

PI: Pulsatility Index

RI: Resistance Index

S:D ratio: Systolic to Diastolic ratio

UA: Umbilical artery

\section{Declarations}

Ethics approval and consent to participate: Research approval for this study was obtained from the Ethics and Research Committee of the Obafemi Awolowo University Teaching Hospitals Complex, Ile-Ife, Nigeria (IRB/IEC/0004553, protocol number ERC/2014/02/04). Consent to participate in the study was obtained from each participant prior to recruitment, with the understanding that they reserve the right to withdraw from the study at any time if they deem it necessary, without any fear.

Consent for publication: Not applicable.

Availability of data and material: The datasets used and/or analysed during the current study are available from the corresponding author on reasonable request

Competing interests: The authors declare that they have no competing interests.

Funding: The study was funding by the Authors. There was no institutional or external fund received.

Authors contribution: IOA, OK and OOB conceived the study. RBO, IOA, CMA, OOS and SBO contributed to the study set-up, quality assurance and study design. IOA, OOS, SAA and OOB contributed to data collection and analysis. All the authors contributed to the preparation of the manuscript and made critical intellectual contributions to the final draft of the manuscript.

Acknowledgement: None.

\section{Tables}


Table 1: Gestational age-specific reference table for fetal umbilical artery resistance index.

Percentiles

$\begin{array}{llllllllll}\text { stational age(weeks) } & 2.5 & 5 & 10 & 25 & 50 & 75 & 90 & 95 & 97.5\end{array}$

$\begin{array}{lllllllll}0.61 & 0.61 & 0.63 & 0.65 & 0.74 & 0.78 & 0.81 & 0.84 & 0.88 \\ 0.54 & 0.54 & 0.56 & 0.65 & 0.69 & 0.74 & 0.80 & 0.82 & 0.85 \\ 0.53 & 0.53 & 0.53 & 0.64 & 0.67 & 0.70 & 0.79 & 0.81 & 0.81 \\ 0.51 & 0.51 & 0.52 & 0.62 & 0.61 & 0.69 & 0.77 & 0.79 & 0.80 \\ 0.46 & 0.46 & 0.49 & 0.55 & 0.60 & 0.68 & 0.71 & 0.76 & 0.79 \\ 0.43 & 0.45 & 0.48 & 0.56 & 0.59 & 0.64 & 0.71 & 0.73 & 0.78 \\ 0.42 & 0.42 & 0.47 & 0.55 & 0.58 & 0.62 & 0.68 & 0.73 & 0.77 \\ 0.38 & 0.38 & 0.46 & 0.53 & 0.57 & 0.62 & 0.66 & 0.71 & 0.77 \\ 0.36 & 0.36 & 0.45 & 0.52 & 0.56 & 0.61 & 0.65 & 0.69 & 0.76 \\ 0.36 & 0.38 & 0.43 & 0.50 & 0.56 & 0.60 & 0.64 & 0.68 & 0.75 \\ 0.35 & 0.40 & 0.42 & 0.50 & 0.55 & 0.60 & 0.62 & 0.67 & 0.74 \\ 0.35 & 0.36 & 0.38 & 0.49 & 0.54 & 0.59 & 0.61 & 0.66 & 0.73 \\ 0.34 & 0.37 & 0.38 & 0.46 & 0.53 & 0.59 & 0.61 & 0.62 & 0.73 \\ 0.34 & 0.36 & 0.37 & 0.43 & 0.53 & 0.58 & 0.60 & 0.61 & 0.72 \\ 0.33 & 0.35 & 0.37 & 0.38 & 0.52 & 0.58 & 0.60 & 0.60 & 0.71\end{array}$


Table 2: Gestational age-specific reference table for fetal umbilical artery pulsatility index

\begin{tabular}{llllllllll}
\hline & \multicolumn{1}{c}{ Percentiles } \\
Gestational age (weeks) & 2.5 & 5 & 10 & 25 & 50 & 75 & 90 & 95 & 97.5 \\
26 & .93 & .93 & 1.02 & 1.14 & 1.18 & 1.27 & 1.47 & 1.50 & 1.52 \\
27 & 0.78 & 0.78 & .81 & 1.00 & 1.08 & 1.19 & 1.40 & 1.49 & 1.50 \\
28 & 0.78 & 0.78 & 0.80 & 0.90 & 0.96 & 1.12 & 1.34 & 1.48 & 1.50 \\
29 & 0.76 & 0.76 & 0.78 & 0.89 & 0.99 & 1.12 & 1.24 & 1.46 & 1.48 \\
30 & 0.65 & 0.65 & 0.69 & 0.85 & 0.96 & 1.10 & 1.23 & 1.41 & 1.41 \\
31 & 0.63 & 0.63 & 0.66 & 0.82 & 0.91 & 1.09 & 1.17 & 1.37 & 1.39 \\
32 & 0.59 & 0.59 & 0.65 & 0.79 & 0.89 & 1.08 & 1.34 & 1.36 & 1.38 \\
33 & 0.56 & 0.56 & 0.63 & 0.77 & 0.88 & 0.99 & 1.22 & 1.36 & 1.36 \\
34 & 0.55 & 0.55 & 0.61 & 0.76 & 0.85 & 0.95 & 1.12 & 1.28 & 1.29 \\
35 & 0.52 & 0.55 & 0.60 & 0.75 & 0.83 & 0.94 & 1.09 & 1.14 & 1.22 \\
36 & 0.49 & 0.54 & 0.59 & 0.72 & 0.81 & 0.93 & 1.02 & 1.10 & 1.21 \\
37 & 0.49 & 0.50 & 0.54 & 0.69 & 0.78 & 0.93 & 1.01 & 1.05 & 1.16 \\
38 & 0.48 & 0.48 & 0.53 & 0.68 & 0.75 & 0.92 & 0.99 & 1.04 & 1.12 \\
39 & 0.47 & 0.47 & 0.52 & 0.65 & 0.70 & 0.90 & 0.99 & 0.99 & 1.10 \\
40 & 0.46 & 0.46 & 0.49 & 0.54 & 0.69 & 0.85 & 0.96 & 0.96 & 1.08 \\
\hline
\end{tabular}

Table 3: Gestational age specific reference chart for fetal umbilical artery Doppler systolic/diastolic ratio. 


\begin{tabular}{lccccccccc}
\cline { 2 - 9 } Gestational age (wks) & $2.5^{\text {th }}$ & $5^{\text {th }}$ & $10^{\text {th }}$ & 25 th & $50^{\text {th }}$ & 75 th & $90^{\text {th }}$ & 95 th & 97.5 th \\
26 & 2.54 & 2.54 & 2.70 & 2.82 & 3.12 & 4.42 & 4.50 & 4.62 & 4.71 \\
27 & 2.00 & 2.00 & 2.27 & 2.73 & 2.99 & 3.20 & 4.20 & 4.44 & 4.69 \\
28 & 2.11 & 2.11 & 2.14 & 2.28 & 2.65 & 3.05 & 4.01 & 4.40 & 4.68 \\
29 & 2.09 & 2.09 & 2.20 & 2.43 & 2.60 & 3.00 & 3.81 & 4.67 & 4.67 \\
30 & 1.73 & 1.73 & 2.09 & 2.12 & 2.52 & 2.90 & 3.78 & 4.50 & 4.58 \\
31 & 1.65 & 1.65 & 1.79 & 2.12 & 2.41 & 2.78 & 3.58 & 4.45 & 4.50 \\
32 & 1.62 & 1.62 & 1.76 & 2.35 & 2.38 & 2.75 & 3.52 & 3.86 & 4.30 \\
33 & 1.62 & 1.62 & 1.74 & 2.02 & 2.35 & 2.70 & 3.32 & 3.40 & 4.00 \\
34 & 1.61 & 1.61 & 1.72 & 2.00 & 2.32 & 2.68 & 2.936 & 3.17 & 3.80 \\
35 & 1.58 & 1.61 & 1.70 & 2.00 & 2.24 & 2.63 & 2.831 & 3.02 & 3.67 \\
36 & 1.57 & 1.58 & 1.60 & 1.99 & 2.22 & 2.59 & 2.89 & 3.00 & 3.50 \\
37 & 1.56 & 1.57 & 1.60 & 1.73 & 2.18 & 2.54 & 2.79 & 2.94 & 3.41 \\
38 & 1.53 & 1.55 & 1.59 & 1.71 & 2.12 & 2.43 & 2.72 & 2.89 & 3.38 \\
39 & 1.50 & 1.53 & 1.54 & 1.59 & 1.98 & 2.42 & 2.75 & 2.8 & 3.35 \\
40 & 1.48 & 1.52 & 1.53 & 1.59 & 1.88 & 2.37 & 2.50 & 2.72 & 3.31 \\
\hline
\end{tabular}

Table 4: Correlation between feto-maternal characteristics and umbilical arterial Doppler indices. 


\begin{tabular}{llll}
\hline Parameter & \multicolumn{3}{c}{ Doppler indices } \\
\cline { 2 - 3 } & RI & PI & SD
\end{tabular}

Maternal age

$\begin{array}{lcrr}\mathrm{R} & -0.12 & -0.09 & -0.11 \\ \mathrm{p} \text {-value } & 0.07 & 0.66 & 0.06\end{array}$

Parity

$\begin{array}{lrrr}\mathrm{R} & -0.04 & -0.04 & -0.04 \\ \mathrm{p} \text {-value } & 0.94 & 0.52 & 0.55\end{array}$

Gestational age

$\begin{array}{llll}\mathrm{R} & -0.46 & -0.42 & -0.41 \\ \mathrm{p} \text {-value } & <0.01 & <0.01 & <0.01\end{array}$

Birthweight

$\begin{array}{llrr}\text { R } & -0.21 & -0.17 & -0.25 \\ \text { p-value } & <0.01 & 0.01 & <0.01\end{array}$

Neonatal gender

$\begin{array}{llll}R & 0.05 & 0.03 & 0.03 \\ & 0.41 & 0.61 & 0.57\end{array}$

$\mathrm{R}=$ Coefficient of correlation

\section{References}

1. World Health Organization and Partnership for Maternal NCH. Stillbirths: The invisible public health problem. Geneva: WHO; 2012.

2. World Health Organization. Maternal, newborn, child and adolescent health: Stillbirth. Geneva: WHO; 2012.

3. Cousens S, Blencowe H, Stanton C, Chou D, Ahmed S, Steinhardt L, et al. National, regional, and worldwide estimates of stillbirth rates in 2009 with trends since 1995: a systematic analysis. Lancet 2011; 377: 1319-30.

4. Haws RA, Yakoob MY, Soomro T, Menezes EV, Darmstadt GL, Bhutta ZA. Reducing stillbirths: screening and monitoring during pregnancy and labour. BMC Pregnan Childbirth 2009; 9: 1-48.

5. Fawole AO, Shah A, Tongo O, Dara K, El-Ladan AM, Umezulike AC, et al. Determinants of perinatal mortality in Nigeria. Int J Gynaecol Obstet. 2011;114:37-42. 
6. Liston R, Sawchuck D, Young D. Fetal health surveillance: antepartum and intrapartum consensus guideline. J Obstet Gynaecol Can 2007;29(9 Suppl 4):S3-56.

7. Gagnon R, Van den Hof M. S O G C Clinical Practice Guidelines: The use of Fetal Doppler in Obstetrics. J Obstet Gynaecol Can 2003; 25(7): 601-7.

8. Alfirevic Z, Stampalija T, Gyte GM. Fetal and umbilical Doppler ultrasound in high-risk pregnancies. Cochrane Database Syst Rev. 2010(1):CD007529.

9. Baschat AA. Venous Doppler evaluation of the growth-restricted fetus. Clin Perinatol. 2011; 38: $103-12$.

10. Stampalija T, Alfirevic Z, Gyte G. Doppler in obstetrics: evidence from randomized trials. Ultrasound Obstet Gynecol. 2010; 36(6): 779-80.

11. Baschat AA, Gembruch U, Reiss I, Gortner L, Weiner CP, Harman CR. Relationship between arterial and venous Doppler and perinatal outcome in fetal growth restriction. Ultrasound Obstet Gynecol. 2000; 16: 407-13.

12. Pourcelot L. Velocimetrie ultrasonore Doppler Seminaire. INSERM 1974. 2: 213-40.

13. Gosling RG, King DH. Arterial assessment by Doppler-shift ultrasound. Proc R Soc Med. 1974; 67: 4479.

14. Stuart B, Drumm J, FitzGerald DE, Duignan NM. Fetal blood velocity waveforms in normal pregnancy. BJOG. 1980; 87(9): 780-5.

15. Harrington K, Carpenter RG, Goldfrad C, Campbell S. Transvaginal Doppler ultrasound of the uteroplacental circulation in the early prediction of pre-eclampsia and intrauterine growth retardation. BJOG. 1997; 104(6): 674-81.

16. Baschat AA. Doppler application in the delivery timing of the preterm growth-restricted fetus: another step in the right direction. Ultrasound Obstet Gynecol. 2004; 23(2): 111-8.

17. Ciobanu A, Wright A, Syngelaki A, Wright D, Akolekar R, Nicolaides K. Fetal Medicine Foundation reference ranges for umbilical artery and middle cerebral artery pulsatility index and cerebroplacental ratio. Ultrasound Obstet Gynecol. 2019; 53(4): 465-72.

18. Ajayi GO. The Effect of Appropriate and Small for Gestational Age Pregnancies on Somatomedin$\mathrm{C}(\mathrm{SMC}) /$ IGF-I), Human Placental Lactogen and Doppler Velocimetry in Nigerian Women. Afr J Endo Metabol. 2002; 3(1): 49-51.

19. Yakasai IA, Tabari MA, Rabiu A, Ismail AM. Pattern of fetal arterial blood flow in selected vessels in patients with pregnancy induced hypertension in Aminu Kano Teaching Hospital Kano, Nigeria. West Afr J Radiol. 2013; 20: 9-13.

20. International Electrotechnical Commission. IEC 60601-2-37 Ed. 2.0. Medical electrical equipment - Part 2-37: Particular requirements for the basic safety and essential performance of ultrasonic medical diagnostic and monitoring equipment. Geneva: IEC: 2007.

21. Bhide A, Acharya G, Bilardo CM, Brezinka C, Cafici D, Hernandez-Andrade E, et al. ISUOG practice guidelines: Use of Doppler Ultrasonography in Obstetrics. Ultrasound Obstet Gynecol. 2013; 41(2): 23339. 
22. Baschat AA. Arterial and venous Doppler in the diagnosis and management of early onset fetal growth restriction. Early Hum Dev. 2005; 81: 877-87.

23. Acharya G, Wilsgaard T, Berntsen GK, Maltau JM, Kiserud T. Reference ranges for serial measurements of umbilical artery Doppler indices in the second half of pregnancy. Am J Obstet Gynecol. 2005; 192: 937-44.

24. Acharya G, Wilsgaard T, Berntsen GK, Maltau JM, Kiserud T. Doppler-derived umbilical artery absolute velocities and their relationship to fetoplacental volume blood flow: a longitudinal study. Ultrasound Obstet Gynecol. 2005; 25(5): 444-53.

25. Acharya G, Wilsgaard T, Rosvold Berntsen GK, Maltau JM, Kiserud T. Reference ranges for umbilical vein blood flow in the second half of pregnancy based on longitudinal data. Prenat Diagn. 2005; 25(2): 99111.

26. Thompson RS, Trudinger BJ, Cook CM. Doppler ultrasound waveform indices: A/B ratio, pulsatility index and Pourcelot ratio. BJOG. 1988; 95: 581-88.

27. Acharya G, Erkinaro T, Makikallio K, Lappalainen T, Rasanen J. Relationships among Doppler-derived umbilical artery absolute velocities, cardiac function, and placental volume blood flow and resistance in fetal sheep. Am J Physiol Heart Circ Physiol. 2004; 286: H1266-28. Acharya G, Wilsgaard T, Berntsen GK, Maltau JM, Kiserud T. Reference ranges for serial measurements of blood velocity and pulsatility index at the intra-abdominal portion, and fetal and placental ends of the umbilical artery. Ultrasound Obstet Gynecol 2005; 26(2): 162-9.

28. Ayoola OO, Bulus P, Loto OM, Idowu BM. Normogram of umbilical artery Doppler indices in singleton pregnancies in south-western Nigerian women. J Obstet Gynae Res. 2016; 42(12): 1694-1698.

\section{Figures}




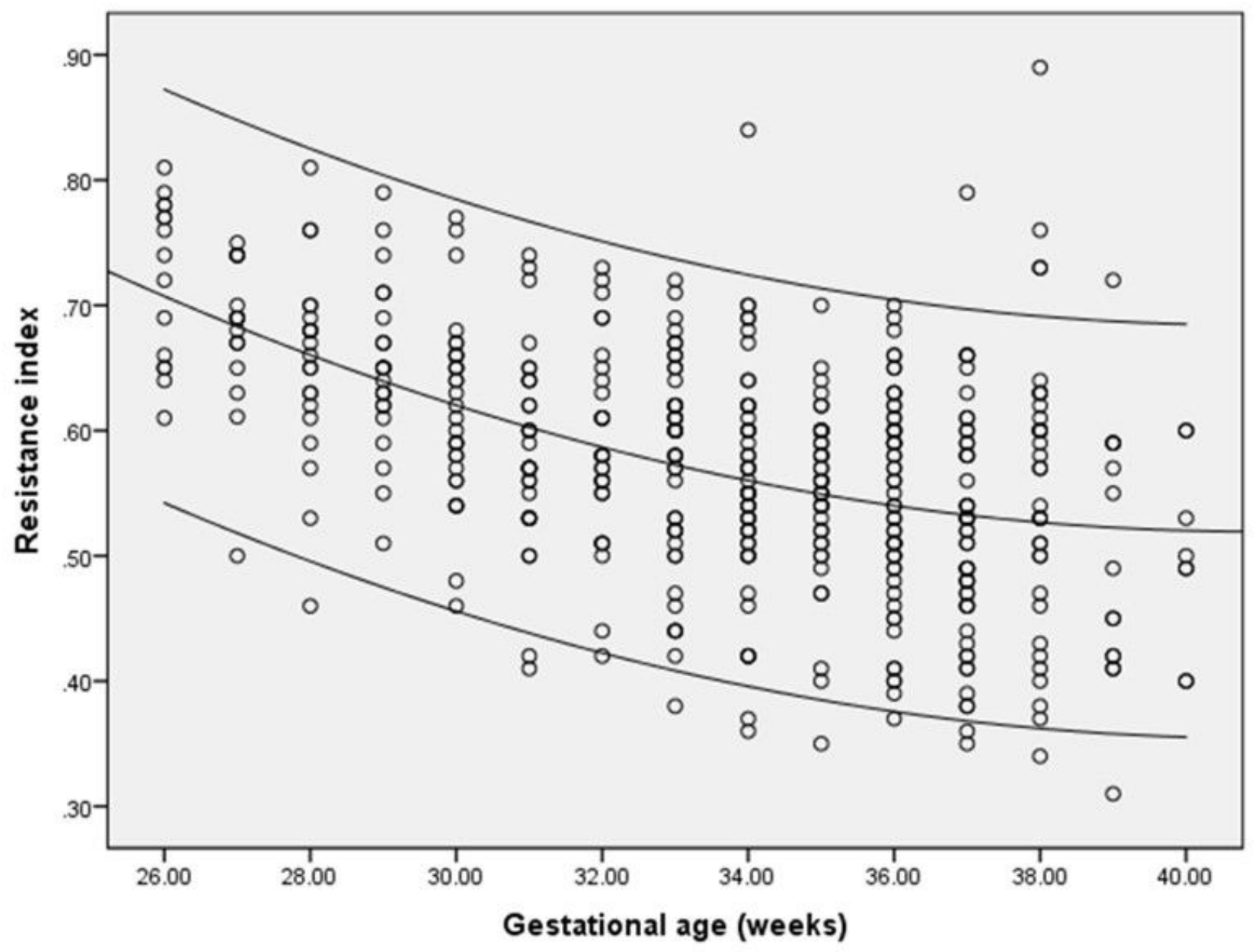

Figure 1

Umbilical Artery Resistance Index showing 2.5th, 50th and 97.5th Centiles. 


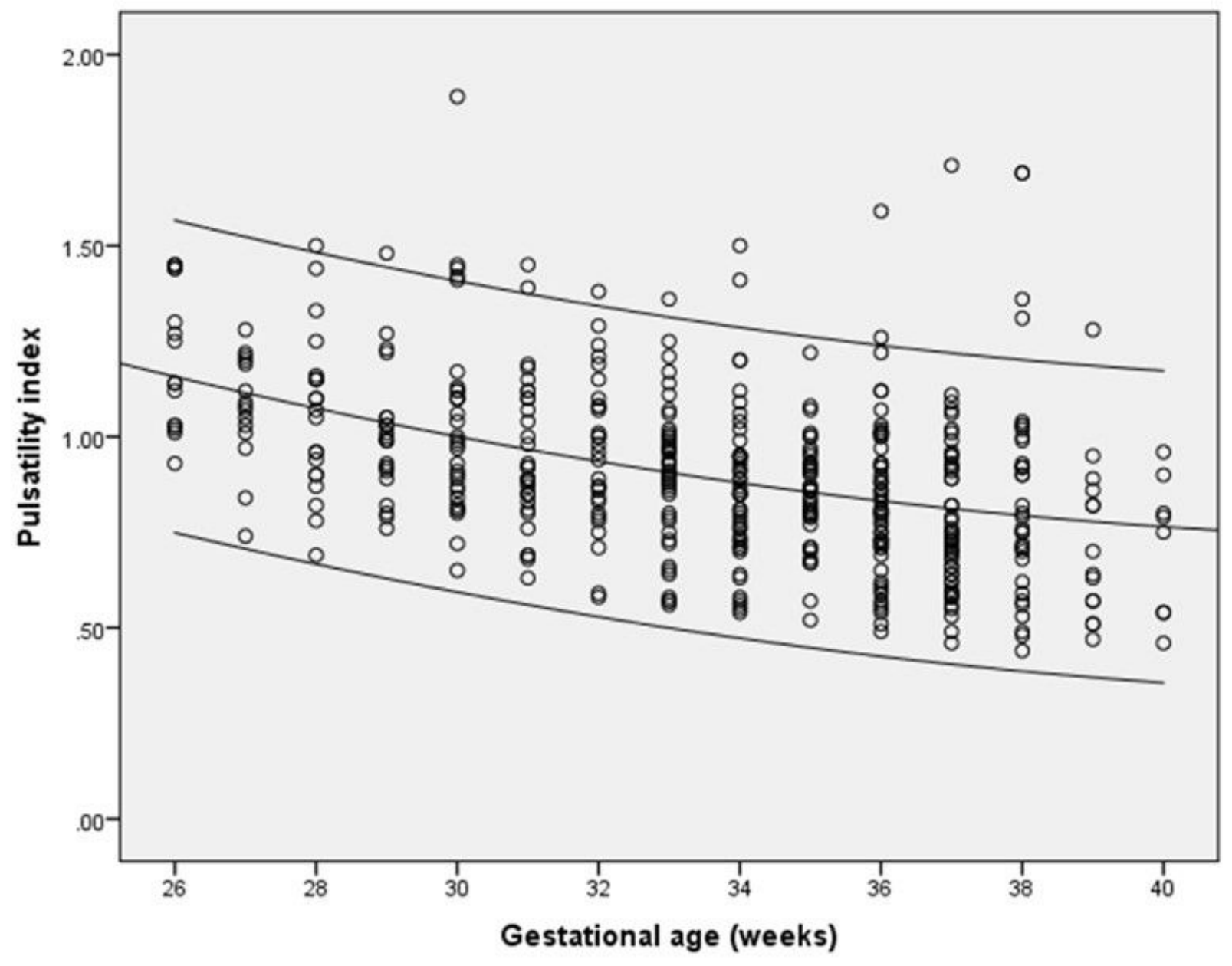

Figure 2

Umbilical Artery Pulsatility Index showing 2.5th, 50th and 97.5th Centiles. 


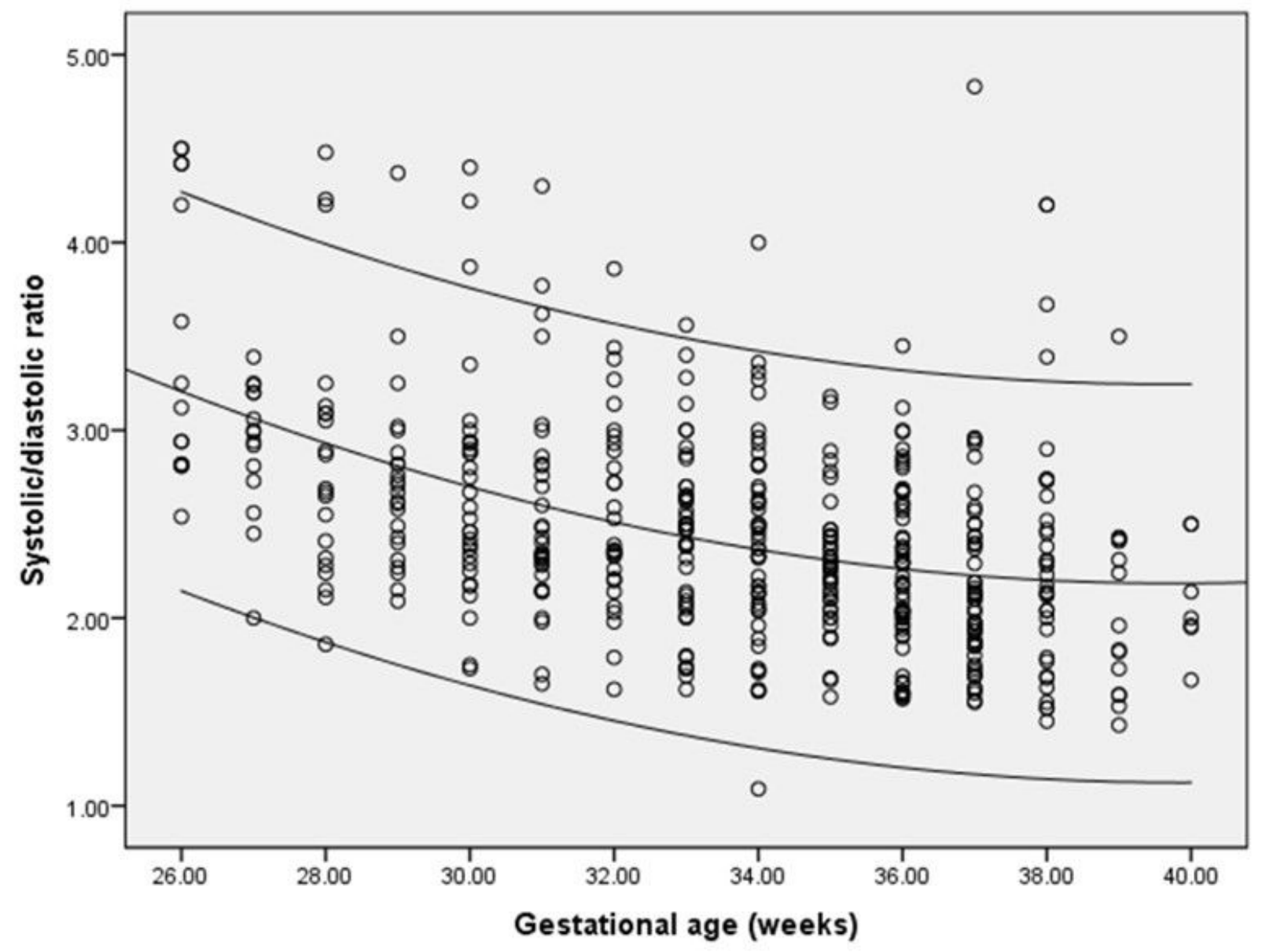

Figure 3

Umbilical Artery Systolic: Diastolic Ratio showing 2.5th, 50th and 97,5th Centiles. 